\section{A EXPERIÊNCIA EDUCACIONAL DOS ATLETAS NOS JOGOS OLÍMPICOS DA JUVENTUDE: UMA REVISÃO SISTEMÁTICA}

\author{
THE EDUCATIONAL EXPERIENCE OF ATHLETES IN YOUTH OLYMPIC \\ GAMES: A SYSTEMATIC REVIEW
}
LA EXPERIENCIA EDUCATIVA DE LOS ATLETAS EN LOS JUEGOS OLIMPICOS DE LA JUVENTUD: UNA REVISIÓN SISTEMÁTICA

Adriano Lopes de Souza*, Otávio Tavares**

\begin{abstract}
Palavras chave: Esportes juvenis. Aprendizagem social.

Revisão sistemática. Adolescente.

Resumo: O objetivo do presente estudo é compreender o que vem sendo produzido na literatura nacional e internacional a respeito da participação dos jovens atletas de elite no Jogos Olímpicos da Juventude, com foco na sua experiência educacional. Para tanto, realizamos uma revisão sistemática qualitativa. As buscas foram realizadas em cinco bases de dados diferenciadas, a partir das quais selecionamos sete artigos em consonância com os critérios de inclusão e exclusão. Os resultados apontaram que a participação nos YOG pode promover um conjunto de aprendizagens valorativas aos jovens atletas. Entretanto, tais experiências educacionais parecem materializar-se muito mais a partir de reuniões e interações socioculturais de caráter informal entre eles. Conclui-se que o sucesso deste novo megaevento não reside em replicar os Jogos Olímpicos como preparação da juventude para atuar nas edições adultas, mas na sua capacidade/potencialidade para equilibrar mais claramente a tríade esporte-competição-educação.
\end{abstract}

Keywords: Youth Sports. Social learning. Systematic review. Adolescent.

Palabras clave: Deportes juveniles. Aprendizaje social. Revisión sistemática. Adolescente.

Abstract: This study aims at understanding what has been produced in national and international literature about participation of young elite athletes in the Youth Olympic Games, focusing on their educational experience. We conducted a qualitative systematic review, with searches in five different databases, where inclusion and exclusion criteria were used to select seven articles. The results showed that participation in YOG can promote a set of value-based learnings for young athletes. However, such educational experiences seem to materialize much more from informal meetings and sociocultural interactions between them. It finds that the success of this new mega event does not lie in replicating the Olympic Games in preparation for youth to perform in the adult editions, but in their ability/ potential to balance the sport-competition-education triad more clearly.

Resumen: El objetivo de este estudio es comprender lo que se ha producido en la literatura nacional e internacional sobre la participación de los jóvenes atletas de élite en los Juegos Olímpicos de la Juventud, centrándose en su experiencia educativa. Con este fin, realizamos una revisión sistemática cualitativa. Las búsquedas se realizaron en cinco bases de datos diferentes, de las cuales seleccionamos siete artículos de acuerdo con los criterios de inclusión y exclusión. Los resultados mostraron que la participación en los YOG puede promover un conjunto de aprendizajes de valor para los jóvenes atletas. Sin embargo, tales experiencias educativas parecen materializarse mucho más a partir de reuniones e interacciones socioculturales de carácter informal entre ellos. Se concluye que el éxito de este nuevo megaevento no radica en replicar los Juegos Olímpicos como preparación para que los jóvenes se presenten en las ediciones para adultos, sino en su capacidad/potencial para equilibrar más claramente la tríada deportecompetición-educación.
*Universidade Federal do Tocantins. Tocantinópolis, TO, Brasil. E-mail: adrianolopes_10@hotmail.com

** Universidade Federal do Espírito Santo. Vitória, ES, Brasil. E-mail:

tavaresotavio@yahoo.com.br

Recebido em: 10-10-2019 Aprovado em: 07-05-2020 Publicado em: 25-05-2020 (c) (i) (8) Licence 


\section{INTRODUÇÃO}

Os megaeventos representam parte significativa da nossa experiência contemporânea e, por isso, devem estar sempre sujeitos ao debate e até mesmo ao escrutínio público (TAVARES, 2011). Dentre os megaeventos de caráter esportivo, mais especificamente, interessa-nos destacar os Jogos Olímpicos (JO), não apenas por reunir os melhores atletas em uma competição de dimensão internacional, mas, por vincular-se explicitamente a uma ideologia olímpica, cujo eixo de referência está circunscrito por um conjunto de valores orientadores (TAVARES, 2003), transcendendo, portanto, um cenário relacionado estritamente à performance dos atletas nos campos, nas arenas e nos demais espaços de competições esportivas.

Com efeito, foi justamente no intuito de explicitar tais ideais valorativos que, em 2007, o Comitê Olímpico Internacional (COI) criou um megaevento inovador: os Jogos Olímpicos da Juventude ou Youth Olympic Games (YOG), cujo público alvo são os jovens atletas de elite, com idades entre 15 e 18 anos. Segundo consta no Princípio $n^{\circ} 6$ da Carta Olímpica, por exemplo, há o pressuposto de que o esporte pode representar um importante instrumento para educar a juventude, visando a construção de um mundo mais justo, harmônico e solidário (COI, 1997).

Destarte, visando a concretização de objetivos educacionais, foi implantado nesta nova modalidade olímpica o Programa de Educação e Cultura ou Culture and Education Programme (CEP), desenvolvendo, ao longo de 12 dias, inúmeras atividades para inspirar os jovens atletas a experimentar o intercâmbio cultural e viver de acordo com os valores olímpicos, numa ambivalência entre o desempenho esportivo e o desenvolvimento humanístico (TURINI et al. 2008; DaCOSTA, 2009; TAVARES, 2009; PARRY, 2012). Por isso, pode-se articular que os YOG não devem ser considerados simplesmente com uma "mini-olímpiada", mas, como o mais proeminente megaevento de caráter esportivo, cultural e educacional para a juventude.

Destarte, diante da supramencionada característica educacional, cultural e valorativa deste megaevento esportivo, nos deparamos com a seguinte questão norteadora: O que vem sendo produzido na literatura nacional e internacional a respeito da experiência dos jovens atletas de elite nos YOG? Isto posto, o presente estudo tem como objetivo compreender o que vem sendo produzido na literatura científica a respeito da participação dos jovens atletas de elite neste megaevento, com foco na sua experiência educacional. Com isso, pretendemos dar visibilidade para as contribuições destes estudos no tocante às experiências de aprendizagem dos protagonistas dos YOG: os jovens atletas.

\section{PROCEDIMENTOS METODOLÓGICOS}

No presente estudo utilizamos os pressupostos de uma revisão sistemática de literatura, com delineamento qualitativo descritivo. Tal método estrutura-se a partir de uma síntese de estudos relacionados a uma questão norteadora, considerando as similaridades e as diferenças entre os mesmos, permitindo não apenas conhecer o panorama de publicações sobre um determinado tema à luz da literatura disponível, 
como a identificação de possíveis lacunas e as perspectivas para pesquisas futuras, com novas possibilidades interpretativas e novos direcionamentos teóricos sobre o objeto estudado (SAVIN-BADEN; MAJOR, 2010; GOMES; CAMINHA, 2014).

Para tanto, realizamos uma consulta nas seguintes bases de dados eletrônicas: SciELO, Scopus, SPORTDiscus, Portal de Periódicos da CAPES e Web of Science. Os descritores utilizados no levantamento dos artigos pertinentes a esta revisão foram: "educação" e "experiência educacional", combinados entre si por meio do operador booleano "OR" e combinados, ainda, com "Jogos Olímpicos da Juventude”, por meio do operador booleano “AND”, em três línguas: português, inglês e espanhol. Incluímos também um recorte temporal de nove anos, abrangendo o período compreendido entre os anos de 2010 e 2019, de tal modo que contemplasse a primeira edição dos YOG até o presente momento.

Foram estabelecidos os seguintes critérios de inclusão: (a) abordar o caráter educacional dos YOG; (b) ter como sujeitos, os jovens atletas olímpicos; (c) estar publicado no período compreendido de 2010 a 2019; (d) estudo empírico, publicado em revista científica no idioma inglês, português ou espanhol, com disponibilidade do texto completo. Em contrapartida, os critérios de exclusão implementados foram: (a) falta de relação direta com o tema; (b) ser realizado com outros sujeitos, sem o envolvimento dos referidos atletas; (c) artigos não publicados, artigos de revisão, artigos de opinião e resenhas críticas, bem como artigos originais que não estavam integralmente disponíveis no idioma inglês, português ou espanhol.

Ademais, no que diz respeito aos procedimentos de busca dos artigos, procedemos inicialmente com uma leitura cuidadosa dos títulos, dos resumos e das respectivas palavras-chave, visando averiguar se tais estudos eram condizentes ou não com os critérios supracitados (de inclusão e exclusão). Por conseguinte, em consonância com a orientação do Centre for Reviews and Dissemination (2008), operamos uma análise criteriosa da qualidade da literatura selecionada a partir da leitura na íntegra dos textos que atenderam aos respectivos critérios.

Diante do exposto, optamos por dar centralidade para os seguintes itens contidos nos artigos selecionados nesta revisão, a saber: objetivo, abordagem metodológica (método e técnicas), localidade (lócus), sujeitos participantes (amostra) e principais resultados. No tocante ao tratamento destes últimos, mobilizamos procedimentos de análise de conteúdo (BARDIN, 2011), cujas categorias foram estabelecidas a posteriori.

\section{RESULTADOS E DISCUSSÃO}

Conforme sintetizado pelo fluxograma abaixo (Figura 1), a procura inicial nas bases de indexação resultou no levantamento de 152 artigos (SciELO = 2; Scopus = 21; SPORTDiscus = 40; Portal de Periódicos da CAPES = 48; Web of Science $=41$ ). Dentre eles, 142 foram excluídos após a leitura dos títulos e resumos, seja por falta de relação direta com a temática de interesse - enfocando aspectos como: turismo, economia política, empreendedorismo, sustentabilidade, nutrição e obesidade -, seja por não incluir os jovens atletas como sujeitos do estudo (pautando-se, por exemplo, 
na perspectiva dos espectadores, dos treinadores e dos voluntários), ou simplesmente por não estarem disponíveis na íntegra e por eliminação dos duplicados. Isto posto, foi selecionado um conjunto de 10 artigos para a leitura na íntegra. Destes, três artigos foram excluídos por se distanciarem da discussão educacional atrelada aos YOG. Assim, um total de 7 publicações cumpriram com todos os critérios pré-estabelecidos e compuseram a amostra final da presente revisão sistemática.

Figura 1 - Fluxograma da seleção e triagem dos estudos incluídos na revisão.

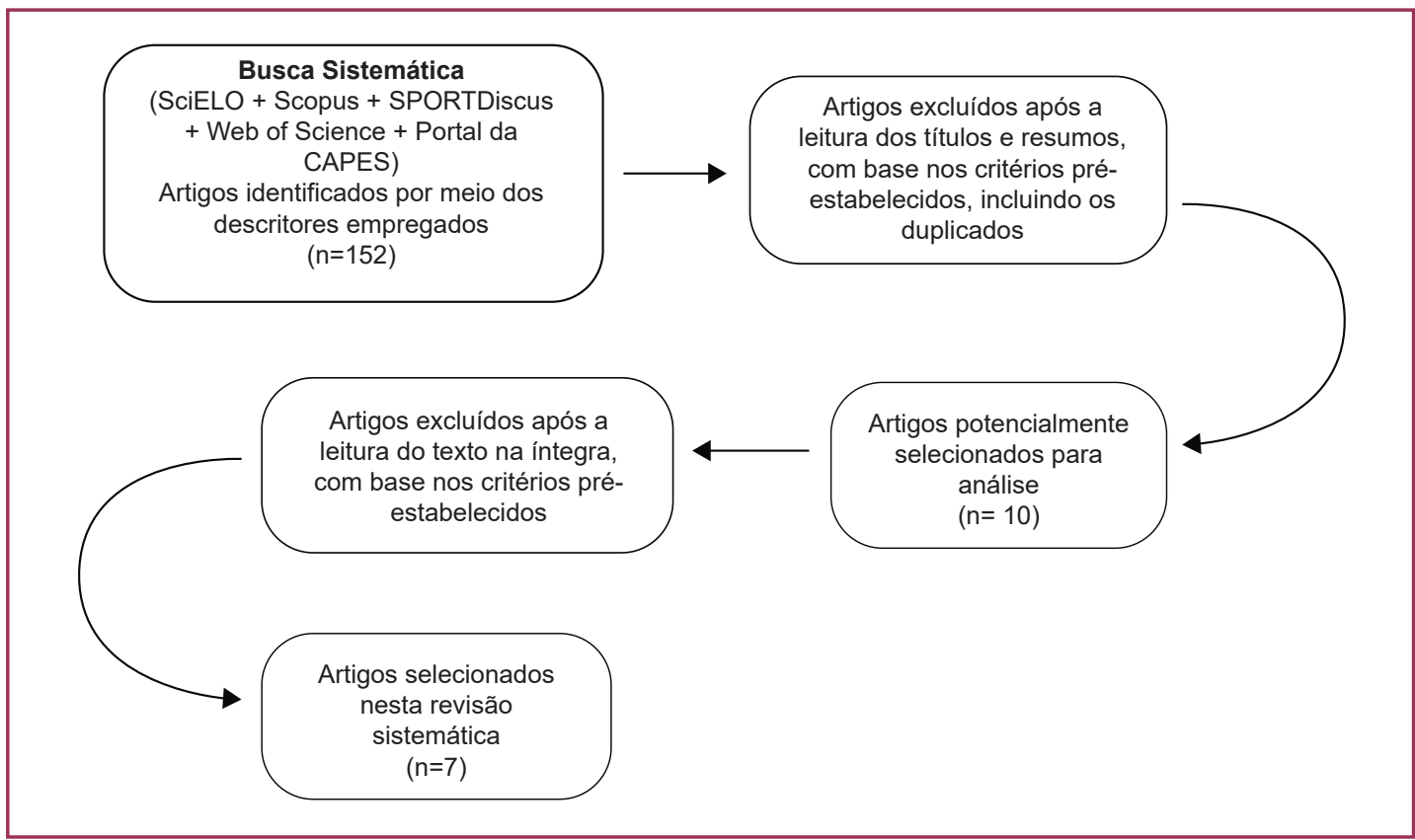

Fonte: Os autores.

Preliminarmente, nos chamou a atenção uma quase totalidade de publicações no idioma inglês, a partir do filtro estabelecido em nossa busca nas referidas bases de dados, representando $98,7 \%$ da nossa amostra inicial. Ou seja, dos 152 artigos inicialmente identificados, apenas 2 estavam no idioma espanhol e nenhum na língua portuguesa. Tal situação pode estar associada ao fato das edições dos YOGs (de verão e de inverno) terem sido realizadas nos continentes asiático e europeu, com exceção da edição mais recente, que ocorreu pela primeira vez na América do Sul, na cidade de Buenos Aires, Argentina, no ano de 2018. A seguir, serão pormenorizados os principais itens contidos nos sete artigos que compuseram a amostra final desta revisão.

\subsection{QUANTO AOS OBJETIVOS}

Conforme ilustrado no quadro 1 , os artigos analisados buscaram dar voz aos verdadeiros protagonistas deste megaevento (os jovens atletas olímpicos), objetivando analisar, compreender, explorar, avaliar, examinar e, portanto, dar visibilidade ao que havia sido experienciado por eles nas edições em que tiveram a oportunidade de competir e participar, com especial interesse para o componente educacional idealizado pelo COI para estes Jogos, o qual materializa-se, mais diretamente, nas atividades empreendidas pelo CEP. 
Compreendemos que tais objetivos são deveras pertinentes, uma vez que o mundo vivido ou experimentado pela ação dos jovens atletas pode conter singularidades por vezes dissonantes daquilo que élhe é previamente-e externamente - projetado. Assim, da mesma forma que o pedestre pode reinventar um percurso diferente em meio à ordem urbana projetada (CERTEAU, 1994), os jovens atletas olímpicos também são capazes de construir sentidos que se aproximam ou que se distanciam daquilo que foi projetado para eles pelo $\mathrm{COI}$.

Por isso, enfocar as experiências destes atletas a partir da interação dialética que eles estabelecem com o outro e com o referido contexto pode ajudar a elucidar a percepção dos mesmos sobre sua participação nos YOGs e, mais especificamente, nas atividades educacionais correlatas.

Quadro 1 - Objetivos dos estudos analisados.

\begin{tabular}{|c|c|}
\hline REFERÊNCIA & OBJETIVOS \\
\hline $\begin{array}{l}\text { Krieger } \\
(2013)\end{array}$ & $\begin{array}{l}\text { Analisar as experiências dos atletas participantes dos YOG e colocar sua } \\
\text { percepção do evento em contraste } \\
\text { com as políticas do COI. }\end{array}$ \\
\hline $\begin{array}{c}\text { Kristiansen } \\
\text { (2013) }\end{array}$ & $\begin{array}{l}\text { Examinar como os atletas noruegueses experimentaram os primeiros YOG } \\
\text { de inverno, equilibrando o programa de competições regulares com o CEP } \\
\text { e o que os atletas percebem como estressores e como eles lidam com isso. }\end{array}$ \\
\hline $\begin{array}{l}\text { Parent; Kristiansen; } \\
\text { Macintosh } \\
(2014)\end{array}$ & $\begin{array}{c}\text { Compreender as experiências de jovens atletas em um festival de } \\
\text { desporto juvenil, especificamente os YOG, destacando as percepções e os } \\
\text { estressores relacionados a tais experiências. }\end{array}$ \\
\hline $\begin{array}{l}\text { Schnitzer; Peters; } \\
\text { Pocecco } \\
(2014)\end{array}$ & $\begin{array}{l}\text { Apresentar um feedback abrangente sobre os primeiros YOG de Inverno da } \\
\text { parte interessada mais importante neste evento: os atletas, destacando sua } \\
\text { percepção a respeito do CEP. }\end{array}$ \\
\hline $\begin{array}{l}\text { Peters; Schnitzer } \\
\qquad(2015)\end{array}$ & $\begin{array}{l}\text { Avaliar a percepção da experiência nos YOG a partir do ponto de vista } \\
\text { dos jovens atletas de elite e de outros grupos de interesse, destacando } \\
\text { expectativas, experiências e legados. }\end{array}$ \\
\hline $\begin{array}{l}\text { Krieger; Kristiansen } \\
\qquad(2016)\end{array}$ & $\begin{array}{c}\text { Explorar a consciência dos jovens alemães e noruegueses participantes } \\
\text { dos YOG acerca da missão educativa } \\
\text { adicional deste novo evento. }\end{array}$ \\
\hline $\begin{array}{l}\text { Macintosh; } \\
\text { Parent; Culver } \\
\quad(2019)\end{array}$ & $\begin{array}{c}\text { Compreender a perspectiva dos jovens atletas sobre o ambiente dos YOG, } \\
\text { destacando suas experiências, } \\
\text { percepções e aprendizagens. }\end{array}$ \\
\hline
\end{tabular}

Fonte: Os autores.

\subsection{QUANTO À ABORDAGEM METODOLÓGICA}

Nenhum dos estudos que compôs essa revisão sistemática especificou o método utilizado no corpo do texto, embora um deles tenha feito menção ao "estudo de caso" no título do artigo. Assim, foram especificadas somente a abordagem metodológica, as técnicas de coleta de dados e os procedimentos empregados.

A abordagem metodológica mais recorrente nestes estudos foi a abordagem qualitativa, presente em cinco deles, cujas principais técnicas utilizadas para a coleta de dados foram as entrevistas semiestruturadas (KRIEGER, 2013; KRISTIANSEN, 2013; KRIEGER; KRISTIANSEN, 2016), o grupo focal (PETERS; SCHNITZER, 2015) e a entrevista semiestruturada, complementada pelas observações no local do 
evento (MACINTOSH; PARENT; CULVER, 2019). Os outros dois estudos operaram por meio de uma abordagem mista, empregando como principais técnicas a aplicação de questionários qualitativos e quantitativos, complementados pelas observações (PARENT; KRISTIANSEN; MACINTOSH, 2014), bem como a união da aplicação de questionários com a composição de grupos focais (SCHNITZER; PETERS; POCECCO, 2014).

\subsection{QUANTO À LOCALIDADE}

Até o presente momento, foram realizadas três edições dos YOG de verão, sediadas em Cingapura (2010), Nanquim (2014) e Buenos Aires (2018), em Singapura, China e Argentina respectivamente; aliadas a duas edições dos YOG de inverno, sediadas em Innsbruck (2012) e Lillehammer (2016), na Áustria e Noruega, respectivamente.

Assim, por se tratarem de estudos empíricos - cujo foco perpassa pela experiência dos jovens atletas -, os artigos analisados têm suas coletas de dados restritas a tais localidades. Destarte, a maior parte da nossa amostra $(71,4 \%)$ optou por investigar os primeiros YOG de inverno, tendo como lócus, portanto, a cidade de Innsbruck (KRISTIANSEN, 2013; PARENT; KRISTIANSEN; MACINTOSH, 2014; SCHNITZER; PETERS; POCECCO, 2014; PETERS; SCHNITZER, 2015), incluindo um estudo que reuniu os dados coletados nesta localidade com os dados coletados outrora na cidade de Cingapura (KRIEGER; KRISTIANSEN, 2016). Assim, os outros dois estudos tiveram como lócus a primeira edição dos YOG, em Cingapura (KRIEGER, 2013) e a segunda edição dos YOG de inverno, em Lillehammer (MACINTOSH; PARENT; CULVER, 2019).

No que tange a localidade dos autores, por sua vez, verifica-se uma predominância do continente europeu, haja vista que cinco dos sete artigos analisados foi composto exclusivamente por pesquisadores da Alemanha, Áustria e/ou Noruega. Além disso, em um dos dois artigos restantes, houve uma mescla de autores do Canadá com uma autora norueguesa, enquanto o último estudo foi composto apenas por pesquisadores canadenses.

\subsection{QUANTO AOS SUJEITOS PARTICIPANTES}

Em consonância com um dos nossos critérios de inclusão, os sujeitos participantes dos artigos analisados inevitavelmente englobaram os jovens atletas. Todavia, um dos estudos analisados também incluiu em sua amostra outros sujeitos que direta ou indiretamente faziam parte do seu contexto de atuação no ambiente dos YOG, a saber: treinadores, embaixadores, chefs de missão e até mesmo atletas modelos ${ }^{1}$.

O quantitativo de sujeitos dos artigos analisados variou de acordo com a abordagem assumida pelos respectivos autores. Nos dois estudos que trabalharam com uma abordagem mista, por exemplo, o quantitativo de sujeitos investigados

\footnotetext{
1 Trata-se de atletas convidados pelo COI para atuarem nos YOG como uma espécie de mentor para os jovens atletas participantes, compartilhando com os mesmos a sua experiência de vida e a sua trajetória esportiva, bem como acompanhando-os em uma série de atividades educacionais na Vila Olímpica da Juventude.
} 
variou entre 89 e 662; já nos estudos com abordagem qualitativa, por sua vez, o número de sujeitos investigados variou entre oito e 36 .

No que diz respeito ao procedimento de seleção dos referidos sujeitos, percebe-se que apenas dois estudos detalharam que foi feito um procedimento de amostragem proposital ou uma amostra intencional (KRISTIANSEN, 2013; KRIEGER; KRISTIANSEN, 2016). Os demais estudos não especificaram este procedimento, mas, da mesma forma que os dois anteriores, buscaram compor as suas amostras com participantes que contemplassem características diversificadas, quais sejam: representatividade de ambos os sexos $(n=7)$; competir em esportes diferenciados; fazer parte de nações e/ou continentes diferentes $(n=5)$; e, até mesmo, obter níveis diferentes de sucesso nas competições esportivas, incluindo medalhistas e não medalhistas $(n=1)$, conforme pode ser verificado no Quadro 2.

Quadro 2 - Sujeitos participantes dos estudos analisados.

\begin{tabular}{|c|c|}
\hline REFERÊNCIA & SUJEITOS PARTICIPANTES \\
\hline $\begin{array}{l}\text { Krieger } \\
(2013)\end{array}$ & $\begin{array}{l}\text { Oito atletas competitivos alemães entre } 16 \text { e } 18 \text { anos de idade, que } \\
\text { participaram dos YOG-2010. Dentre eles, cinco eram do sexo masculino e } \\
\text { três do sexo feminino, os quais competiram em } \\
\text { cinco esportes diferentes. }\end{array}$ \\
\hline $\begin{array}{l}\text { Kristiansen } \\
\text { (2013) }\end{array}$ & $\begin{array}{l}\text { Nove jovens atletas da equipe norueguesa incluídos (três homens e seis } \\
\text { mulheres com idades entre } 17 \text { e } 18 \text { anos). Destes, quatro atletas foram } \\
\text { entrevistados em Innsbruck, após terminarem seus eventos competitivos de } \\
\text { forma precoce; enquanto os outros cinco foram entrevistados no prazo de } \\
\text { algumas semanas após voltar para a Noruega. }\end{array}$ \\
\hline $\begin{array}{l}\text { Parent; Kristiansen; } \\
\text { Macintosh (2014) }\end{array}$ & $\begin{array}{c}27 \text { atletas da equipe norueguesa ( } 13 \text { mulheres e } 14 \text { homens) e } 28 \text { atletas da } \\
\text { equipe canadense ( } 7 \text { mulheres e } 21 \text { homens). }\end{array}$ \\
\hline $\begin{array}{l}\text { Schnitzer; Peters; } \\
\text { Pocecco } \\
\text { (2014) }\end{array}$ & $\begin{array}{c}662 \text { jovens atletas, } 346 \text { homens }(52,3 \%) \text { e } 316 \text { mulheres }(47,7 \%) \text {, cuja } \\
\text { maioria fazia parte do continente europeu }(60 \%) \text {, seguido pela Ásia }(19,5 \%) \text {, } \\
\text { América do Norte }(10,5 \%) \text { e demais continentes (6\%); Destes, } 43 \text { atletas } \\
\text { de } 17 \text { nações diferentes, compuseram os grupos focais competindo em } \\
\text { oito esportes diferentes. As entrevistas foram realizadas em inglês, francês, } \\
\text { alemão e russo. }\end{array}$ \\
\hline $\begin{array}{l}\text { Peters; Schnitzer } \\
\qquad(2015)\end{array}$ & $\begin{array}{l}89 \text { participantes. Destes, } 43 \text { eram jovens atletas de } 17 \text { nações diferentes, } \\
\text { competindo em oito esportes diferentes; enquanto o restante dos sujeitos } \\
\text { eram treinadores, embaixadores, chefs de missão ou atletas modelos. As } \\
\text { entrevistas foram realizadas em inglês, francês, alemão e russo. }\end{array}$ \\
\hline $\begin{array}{l}\text { Krieger; Kristiansen } \\
\qquad(2016)\end{array}$ & $\begin{array}{l}22 \text { jovens atletas. Dentre eles, oito alemães entre } 16 \text { e } 18 \text { anos de idade, que } \\
\text { participaram dos YOG-2010 (cinco eram do sexo masculino e três do sexo } \\
\text { feminino), os quais competiram em seis esportes diferentes (natação, Salto, } \\
\text { Salto com vara, Vela, Esgrima, Corrida de } 400 \mathrm{~m} \text { ) e com diferentes níveis } \\
\text { de sucesso nas competições YOG (medalhistas e não medalhistas); e } 10 \\
\text { atletas noruegueses e } 4 \text { alemães que participaram dos YOG-2012, os quais } \\
\text { competiram em } 11 \text { esportes diferentes. }\end{array}$ \\
\hline $\begin{array}{l}\text { Macintosh; } \\
\text { Parent; Culver } \\
\quad(2019)\end{array}$ & $\begin{array}{c}36 \text { jovens atletas ( } 15 \text { do sexo feminino e } 21 \\
\text { Do sexo masculino), representando } 24 \text { NOCs, todos } \\
\text { os continentes, e } 14 \text { disciplinas desportivas. As entrevistas } \\
\text { foram realizadas em inglês e francês. }\end{array}$ \\
\hline
\end{tabular}

Fonte: Os autores.

A este respeito, destaca-se a dificuldade de acesso aos referidos sujeitos de pesquisa (majoritariamente atletas de alto rendimento). Ora, conforme argumentado 
em um dos estudos, o COI é uma instituição que busca restringir ao máximo o acesso aos seus atletas durante seus eventos (PARENT; KRISTIANSEN; MACINTOSH, 2014), limitando as possibilidades de desenvolver pesquisas com este público-alvo. Assim, com exceção dos eventuais casos em que o estudo já conta previamente com o apoio/patrocínio do $\mathrm{COI}$, muitos pesquisadores necessitam se desdobrar para conseguir operacionalizar suas pesquisas com tal público. Em um dos estudos, por exemplo, os autores tiveram que costurar um acordo com o referido Comitê, assegurando-Ihe o envio de um relatório pós-Jogos acerca das experiências e percepções dos atletas em troca do acesso aos mesmos no decorrer dos Jogos (MACINTOSH; PARENT; CULVER, 2019). Destarte, tal obstáculo pode ajudar a justificar o baixo número de estudos encontrados por nós em diferentes bases de indexação.

Ainda a respeito deste item, há um segundo e importante aspecto que também é digno de nota. A despeito da tentativa destes estudos em diversificar as suas amostras, observa-se que, a rigor, o foco concentrou-se nos jovens atletas da América do Norte e do continente europeu, em especial, os canadenses, alemães e noruegueses - principais nacionalidades dos pesquisadores -, haja vista que mesmo as pesquisas que relataram ter contemplado nações de diferentes continentes, limitaram-se a realizar o processo de entrevista no idioma inglês, francês, alemão e russo. Desta forma, pode-se articular que os atletas sul-americanos, por exemplo, foram sub-representados nestas pesquisas, em comparação com os norteamericanos e europeus, representando, portanto, uma notória lacuna na produção do conhecimento.

\subsection{QUANTO AOS PRINCIPAIS RESULTADOS}

Após a leitura exploratória dos sete artigos incluídos nesta revisão, com o intuito de identificar e organizar as características centrais e os elementos-chave contidos nos seus principais resultados, foram construídas duas categorias de análise, a saber: 1- Objetivos educacionais: Possibilidades e contingências; 2Objetivos educacionais: Desafios e resistências. A seguir, serão apresentados e discutidos, respectivamente, os elementos que mais se aproximam e os elementos que concorrem com os objetivos educacionais - tal como idealizado pelo $\mathrm{COI}$-, tomando como base a perspectiva dos jovens atletas olímpicos a respeito da sua participação singular em uma das edições dos YOG.

\subsubsection{Objetivos educacionais: possibilidades e contingências}

O primeiro aspecto a ser destacado como uma possibilidade educacional nos YOG se refere ao primeiro grande momento destinado para reunir e apresentar todos os atletas, juntamente com o fomento dos símbolos olímpicos: trata-se da cerimônia de abertura. Esta é apontada por eles como sendo uma experiência forte, marcante ou emocionante (KRIEGER; KRISTIANSEN, 2016), bem como uma grande plataforma de aprendizagem intercultural, incentivando, por exemplo, o conhecimento geográfico dos atletas (PETERS; SCHNITZER, 2015). 
O segundo aspecto que merece destaque, diz respeito a exigência do COI para que os jovens atletas permaneçam na Vila Olímpica da Juventude ou Youth Olympic Village (YOV) durante todo o evento, diferindo-se, por exemplo, dos JO tradicionais, nos quais os atletas retornam imediatamente para seus países após concluírem seus compromissos esportivos. Assim, os jovens atletas dispõem de maiores oportunidades para conhecer e fazer amizade com atletas de diferentes culturas na YOV, bem como para participar de diferentes atividades educacionais oferecidas pelo CEP (KRIEGER, 2013).

Conforme apontado por Schnitzer, Peters e Pocecco (2014), os questionários respondidos pelos jovens atletas revelaram que, ao participarem das atividades do CEP, eles puderam reunir um conjunto de aprendizagens a respeito dos seguintes aspectos: valores olímpicos $(86,1 \%)$; outras culturas $(83,2 \%)$; gerenciamento de suas carreiras futuras como atletas de elite (80 \%); expressão das suas próprias opiniões (74,6 \%); senso de responsabilidade social (69,3\%); prevenção de lesões no desporto e melhoria do estilo de vida (62,9\%). Peters e Schnitzer (2015) acrescentam que aqueles atletas que puderam participar das atividades do CEP gostavam de partilhar as suas experiências com os outros, reconhecendo o grande esforço dos organizadores para fornecer benefícios adicionais e contribuir com o seu processo formativo, ou seja, para além do compromisso esportivo.

Assim, o CEP foi visto por alguns atletas de diferentes nacionalidades como um programa capaz de promover uma maior interação social entre eles e, por consequência, a possibilidade de fazer novos amigos, relacionando-se ao valor da Amizade (MACINTOSH; PARENT; CULVER, 2019), além de prepará-los para os desafios futuros, como por exemplo, as formas de lidar com a mídia e até mesmo conceder entrevistas para canais de rádio ou TV, aprimorando, desta maneira, suas habilidades de comunicação (PETERS; SCHNITZER, 2015). Logo, verifica-se que a participação nos YOG em geral e nas atividades do CEP em particular, pode propiciar um aprendizado que transcende as questões relacionadas ao desempenho físico e esportivo dos jovens atletas, mas englobam também uma reflexão sobre seu desenvolvimento psicológico, emocional e social.

Dentre os aspectos mais apreciados pelos atletas de diferentes países acerca da sua experiência na YOV, destacam-se as visitas dos atletas modelos, os quais falavam não apenas sobre suas façanhas e desafios no esporte, mas enfatizavam continuamente a importância da educação ao longo de uma carreira de alto desempenho, explorando aspectos como doping, segurança, formas de agir, etc. (KRIEGER; KRISTIANSEN, 2016). Assim, os encontros com tais atletas modelos foram considerados importantes para o seu desenvolvimento pessoal e para atenuar o aspecto competitivo, uma vez que o foco não concentrava-se apenas no seu desempenho esportivo (KRISTIANSEN, 2013; PETERS; SCHNITZER, 2015). Além disso, a presença dos atletas modelos (ou estrelas, como os jovens atletas os chamavam), serviu, ainda, como um importante incentivo para que os jovens atletas participassem das respectivas atividades do CEP (SCHNITZER; PETERS; POCECCO, 2014). 
Outro aspecto significativo apreciado foi o "YOGGER", um dispositivo USB cedido pela comissão organizadora dos YOG, funcionando como um grande facilitador para a troca de informações entre os atletas, isto é, como uma espécie de "quebra-gelo", conforme apontado por alguns deles (PARENT; KRISTIANSEN; MACINTOSH, 2014). Assim, o YOGGER foi percebido pelos atletas como uma ideia útil para o estabelecimento do primeiro contato com outros atletas, visando a manutenção do contato pós-jogos através das redes sociais (PETERS; SCHNITZER, 2015; KRIEGER; KRISTIANSEN, 2016; MACINTOSH; PARENT; CULVER, 2019).

Em contrapartida, ao serem questionados, por exemplo, sobre o que os jovens atletas haviam apreciado nos YOG em geral, a participação nas atividades do CEP foi apontada por cerca de $72 \%$ da amostra, em comparação com aqueles que preferiam as disputas esportivas (96,6 \%), ou a convivência na YOV $(93,3 \%)$, ou os passeios na cidade de Innsbruck $(93,2 \%)$, ou, ainda, a oportunidade de conhecer atletas olímpicos de outras culturas $(87,2 \%)$, denotando, portanto, que as atividades educacionais do CEP eram comparativamente menos apreciadas na perspectiva dos referidos sujeitos (SCHNITZER; PETERS; POCECCO, 2014).

De fato, muitos atletas afirmaram que ficaram encantados após experimentarem a atmosfera internacional e intercultural presente neste megaevento, por meio da sua cerimônia de abertura, perpassando pelas suas competições esportivas e, em especial, a partir da convivência com os atletas de diferentes localidades, compartilhando um conjunto de experiências, gostos e aspirações nas dependências da YOV (PARENT; KRISTIANSEN; MACINTOSH, 2014; MACINTOSH; PARENT; CULVER, 2019). Até mesmo o momento de se alimentarem na sala de jantar foi apontado por eles como uma rica e importante experiência cultural (KRIEGER; KRISTIANSEN, 2016). Tais aspectos, inclusive, serviram para estreitar laços não apenas entre atletas de diferentes culturas, como também entre as próprias equipes nacionais (PETERS; SCHNITZER, 2015).

Contudo, interessante notar que muitos atletas associaram essa memorável experiência valorativa, educacional e cultural ao simples fato de estarem ali na YOV e não necessariamente ao participarem das atividades planejadas e organizadas pelo CEP (KRIEGER, 2013; PARENT; KRISTIANSEN; MACINTOSH, 2014; KRIEGER; KRISTIANSEN, 2016). Portanto, embora aproximem-se dos objetivos formativos e educacionais - em especial, quanto ao internacionalismo, ao intercâmbio cultural e à construção de amizades -, tais resultados parecem ter sido, em alguma medida, contingenciais, materializando-se a partir de reuniões e interações socioculturais de caráter informal entre os referidos sujeitos.

\subsubsection{Objetivos educacionais: desafios e resistências}

Apesar da possibilidade/obrigatoriedade da sua estadia na YOV durante todo o evento, muitos atletas ainda tiveram escassas experiências no CEP ou simplesmente não participaram das suas atividades educacionais. As razões apontadas por eles são variadas. Alguns alegaram falta de oportunidades, decorrente de um cronograma extenso de competições; outros, falta de interesse, ao considerar tais atividades como 
"infantis" e, portanto, inadequadas para suas idades; outros, priorizaram ver seus companheiros de equipe competindo; outros, ainda, porque optaram por usar o seu tempo de folga para descansar e recuperar entre suas competições (KRIEGER, 2013; PARENT; KRISTIANSEN; MACINTOSH, 2014; SCHNITZER; PETERS; POCECCO, 2014; KRIEGER; KRISTIANSEN, 2016).

O foco na competição esportiva também pode ser destacado como um fator que concorreu com as possibilidades educacionais advindas das atividades do CEP. Afinal, os mesmos atletas que apreciavam o clima interativo e amigável da YOV e que consideraram as iniciativas do CEP como uma boa alternativa para conhecer novas culturas e fazer amigos, por exemplo, também apontaram que estavam ali, em primeiro lugar, para competirem e tentar ganhar o maior número de medalhas possíveis (SCHNITZER; PETERS; POCECCO, 2014). Afinal, conforme argumentado por alguns deles, essa é uma competição que se disputa uma única vez na vida (KRIEGER; KRISTIANSEN, 2016). Aliás, os eventos competitivos inovadores, com equipes mistas - por sexo e por continente -, por exemplo, embora tenham sido considerados agradáveis, acabaram gerando um certo estranhamento por parte dos atletas. Para eles, as competições regulares gozam de maior prestígio e, por isso, são mais atraentes na busca pela medalha olímpica (KRISTIANSEN, 2013; KRIEGER; KRISTIANSEN, 2016).

De fato, por se tratarem de atletas de elite em suas categorias, a dimensão esportiva - através do seu desempenho atlético nas competições - representou o aspecto mais dominante para os jovens atletas de elite nos YOG, relacionando-se ao valor da excelência (PETERS; SCHNITZER, 2015; KRIEGER; KRISTIANSEN, 2016; MACINTOSH; PARENT; CULVER, 2019). Tal excelência para os jovens atletas foi expressa como o esforço para ser o melhor no seu esporte, numa busca contínua pela vitória, mas, ancorada por uma noção de fair play - relacionada ao valor do respeito -, conforme experienciaram com as iniciativas do CEP (MACINTOSH; PARENT; CULVER, 2019). Logo, a participação nestas atividades interativas também foi apontada como um aspecto que contribuiu para formar a base da sua experiência, consistindo, neste caso, em um dos possíveis e importantes legados deste megaevento (PETERS; SCHNITZER, 2015).

Ora, no tocante à discussão sobre os legados resultantes dos megaeventos esportivos, Reppold Filho (2013) destaca que estes podem ser vistos por diferentes caracterizações: positivos ou negativos, intencionais ou não intencionais, tangíveis ou intangíveis, etc. Dentre elas, Romera (2014) adverte-nos para a necessidade de olharmos mais atentamente para os aspectos intangíveis - conforme identificado acima -, cujos desdobramentos interferem diretamente sobre diferentes dimensões sociais, tais como: saúde pública, prevenção ao uso de drogas e diminuição da violência nos estádios.

Por fim, com base na perspectiva dos próprios atletas, é imperioso sublinhar que algumas medidas poderiam ser tomadas pelo comitê organizador na tentativa de minimizar a baixa participação dos mesmos nas referidas atividades educacionais promovidas pelo CEP, são elas: oportunizar atividades diferenciadas para contemplar diferentes idades dos atletas, visto que jovens com 15 ou com 18 anos de idade têm gostos e preferências diferentes; incluir temas mais próximos da sua 
realidade contextual, isto é, temas que elencassem, por exemplo, a conciliação da escola, vida familiar e esporte; investir na visita de mais atletas modelos na YOV para compartilhar suas histórias (PARENT; KRISTIANSEN; MACINTOSH, 2014; KRIEGER; KRISTIANSEN, 2016).

Outras providências também foram mencionadas, quais sejam: organizar de forma mais equilibrada o cronograma de competições esportivas dos diferentes atletas; instruir os jovens embaixadores, os representantes de cada Comitê Olímpico Nacional e os próprios treinadores das diferentes delegações para desempenharem uma comunicação mais eficaz com os jovens atletas acerca da existência e, sobretudo, do real propósito do programa educacional, incentivando-os a participarem das suas respectivas atividades (SCHNITZER; PETERS; POCECCO, 2014), visto que alguns atletas não tinham informações prévias a respeito das mesmas, bem como as consideravam como mero entretenimento ou distração cultural (KRISTIANSEN, 2013).

\section{CONSIDERAÇÕES FINAIS}

Os resultados demonstraram que não há, ainda, uma justa medida entre o discurso oficial do COI e as expectativas, experiências, percepções e preferências dos jovens atletas olímpicos, sobretudo, no que diz respeito à fruição das iniciativas do CEP para a efetivação dos objetivos educacionais atrelados aos YOG.

Por um lado, os resultados indicam que algumas iniciativas do CEP foram apreciadas pelos jovens atletas que se propuseram a participar das suas atividades, representando, neste caso, um dos possíveis e importantes legados intangíveis deste megaevento esportivo. Por outro lado, verifica-se que muitas aprendizagens dos atletas nos YOG - em especial, quanto ao internacionalismo, ao intercâmbio cultural e à construção de amizades - parecem ter sido, em alguma medida, contingenciais, materializando-se muito mais a partir de reuniões e interações socioculturais de caráter informal entre eles. Ademais, observa-se que tais atividades sistematizadas do CEP parecem não gozar de uma grande popularidade por boa parte dos atletas investigados, os quais, por diferentes e múltiplas razões, apresentam uma resistência ou dificuldade de participação.

Assim, compreende-se que tal intento educativo requer uma reflexão, quiçá uma reavaliação de toda a programação educacional e cultural por parte do comitê organizador dos YOG, no intuito de gerar maiores condições para que os jovens atletas possam experimentar plenamente o espírito olímpico e as possibilidades educacionais correlatas a um megaevento esportivo que pretende transcender a dimensão competitiva.

Por fim, os dados expostos nesta revisão sugerem que a busca pelo equilíbrio entre a competição esportiva e os objetivos culturais e educacionais é um desafio necessário para a formatação de um megaevento esportivo, em especial, para o público mais jovem, como é o caso dos YOG. Conclui-se, portanto, que o seu sucesso não reside na tentativa de reproduzir os JO tradicionais para a juventude, como uma espécie de "mini-olímpiada", destinada a prepará-la para atuar nas edições adultas, 
mas, na sua capacidade ou potencialidade para equilibrar mais claramente a tríade esporte, competição e educação.

\section{REFERÊNCIAS}

BARDIN, Laurence. Análise de conteúdo. São Paulo: Edições 70, 2011.

CENTRE FOR REVIEWS AND DISSEMINATION. Systematic Reviews: CRD's guidance for undertaking reviews in health care. York: University of York, 2008. Disponível em: http:// www.york.ac.uk/media/crd/Systematic Reviews.pdf. Acesso em: 17 maio 2019.

CERTEAU, Michel de. A invenção do cotidiano: as artes de fazer. Petrópolis: Vozes, 1994.

COI - COMITÊ OLÍMPICO INTERNACIONAL. Olympic charter. Lausanne: COI, 1997. Disponível em: https://stillmed.olympic.org/Documents/Olympic\%20Charter/Olympic Charter_through_time/1997-Olympic_Charter.pdf. Acesso em: 15 jul. 2019.

DaCOSTA, Lamartine Pereira. Educação Olímpica como metalinguagem axiológica: revisões pedagógicas e filosóficas de experiências internacionais e brasileiras. In: REPPOLD, Alberto et al. (orgs.). Olimpismo e Educação Olímpica no Brasil. Porto Alegre: Ed. UFRGS, 2009. p. 17-28.

GOMES, Isabelle Sena; CAMINHA, Iraquitan Oliveira. Guia para estudos de revisão sistemática: uma opção metodológica para ciências do movimento humano. Movimento, v. 20, n. 1, p. 395-411, jan./mar. 2014.

KRIEGER, Jörg; KRISTIANSEN, Elsa. Ideology or reality? The awareness of

Educational aims and activities amongst German and Norwegian participants of the first summer and winter Youth Olympic Games. Sport in Society, v. 19, n. 10, p. 1503-1517, 2016.

KRIEGER, Jörg. Fastest, highest, youngest? Analysing the athlete's experience of the Singapore Youth Olympic Games. International Review for the Sociology of Sport, v. 48, n. 6, p. 706-719, 2013.

KRISTIANSEN, Elsa. Competing for culture: Young Olympians' narratives from the first winter Youth Olympic Games. International Journal of Sport and Exercise Psychology, v. 13, n. 1, p. 29-42, 2013.

MACINTOSH, Eric; PARENT, Milena; CULVER, Diane. Understanding Young Athletes' Learning at the Youth Olympic Games: A Sport Development. Journal of Sport Management Global, 2019. https://doi.org/10.1080/24704067.2018.1561206.

PARENT, Milena; KRISTIANSEN, Elsa; MACINTOSH, Eric. Athletes' experiences at the Youth Olympic Games: Perceptions, stressors and discourse paradox. Event Management, v. 18, n. 3, p. 303-324, 2014.

PARRY, Jim. The Youth Olympic Games - some Ethical Issues. Sport, Ethics and Philosophy, v. 6, n. 2, p. 138-154, 2012.

PETERS, Mike; SCHNITZER, Martin. Athletes' Expectations, Experiences, and Legacies of the Winter Youth Olympic Games Innsbruck 2012. Journal of Convention \& Event Tourism, v. 16, n. 2, p. 116-144, 2015. 
REPPOLD FILHO, Alberto Reinaldo. Megaeventos esportivos e ciências do esporte no Brasil. In: TONDIN, G.; VIDAL, J.R.; FEIX, E. (Orgs.). Esporte e lazer no Brasil: divisão de responsabilidades entre os entes federativos. Porto Alegre: Companhia Rio-grandense de Artes Gráficas, 2013, p. 113-128.

ROMERA, Liana Abrão. Copa do Mundo e cerveja: impactos intangíveis de um megaevento. Movimento, v. 20, n. 2, p. 775-798, abr./jun. 2014.

SAVIN-BADEN, Maggi; MAJOR, Claire Howell. Qualitative Research Synthesis: The Scholarship of Integration in Practice. In: SAVIN-BADEN, Maggi; MAJOR, Claire Howell. New Approaches to Qualitative Research: Wisdom and Uncertainty. Oxon: Routledge, 2010. p. 108-118.

SCHNITZER, Martin; PETERS, Mike; POCECCO, Elena. Perception of the Culture and Education Programme of the Youth Olympic Games by the Participating Athletes: A Case Study for Innsbruck 2012. International Journal of History of Sport, v. 31, n. 9, p. 11781193, 2014.

TAVARES, Otávio. Educação Olímpica para o Rio de Janeiro 2016: princípios, temas, estratégias, meios e elementos. In: REPPOLD, Alberto et al. (orgs.). Olimpismo e educação olímpica no Brasil. Porto Alegre: Editora da UFRGS, 2009. p. 191-200.

TAVARES, Otávio. Esporte, movimento olímpico e democracia: o atleta como mediador. 2003. Tese (Doutorado em Educação Física) - Universidade Gama Filho, Rio de Janeiro, 2003.

TAVARES, Otávio. Megaeventos esportivos. Movimento, v. 17, n. 3, p. 11-35, jul./set. 2011.

TURINI, Márcio et al. Jogos Olímpicos da Juventude: um novo megaevento esportivo de sentido educacional focado em valores. In: RODRIGUES, Rejane Penna et al. (orgs.)

Legados de Megaeventos Esportivos. Brasília: Ministério dos Esportes, 2008. p. 377-382. 